1. MBBS, FCPS
Senior Registrar
Department of Gyne \&Obs
HBS Medical and Dental College/
General Hospital, Islamabad.
2. MBBS, FCPS
Specialist Registrar
Department of Gyne \&Obs
HMC, Peshawar.
3. MBBS, FCPS
Assistant Professor
Department of Gyne \&Obs
HMC, Peshawar.
4. PhD. (Biochemistry \& Molecular
Biology)
Assistant Professor
KMU, Peshawar.
5. MBBS, FCPS
Assistant Professor
Department of Gyne \&Obs
HBS Medical and Dental College/
General Hospital, Islamabad.
6. MBBS, FCPS
Assistant Professor
Department of Gyne \&Obs
HBS Medical and Dental College/
General Hospital, Islamabad.

Correspondence Address: Dr. Dureshahwar

House No. 2B, Unique Road,

Rawalpindi.

dureshahwar72@yahoo.com

Article received on:

31/12/2018

Accepted for publication:

15/03/2019

Received after proof reading:

$30 / 09 / 2019$

\section{FREQUENCY OF PLACENTAL INFARCTS IN PATIENTS WITH SEVERE PLACENTAL ABRUPTION.}

\begin{abstract}
Dureshahwar ${ }^{1}$, Sanodia Afridi ${ }^{2}$, Rubina Akhter ${ }^{3}$, Irshad Ahmad ${ }^{4}$, Sajida Asghar ${ }^{5}$, Saniya Naheed ${ }^{6}$
ABSTRACT... Peripheral infarcts on maternal side are relatively common and are not thought to be clinically significant. However those that occupy more than $5 \%$ of the placental mass or are more than $3 \mathrm{~cm}$ in diameter in size are associated with perinatal mortality and morbidity. Objectives: To determine the frequency of placental infracts and its different severity grades among women with severe placental abruption. Study Design: Cross sectional descriptive study. Setting: Department of Obstetrics \& Gynaecology, Postgraduate Medical Institute, Lady Reading Hospital Peshawar. Period: January 2016 to July 2016. Material and Methods: Patients admitted in hypovolemic shock or intrauterine fetal death was considered as severe abruption. Placenta of the subject was collected from labour room of the wards and was fixed in $10 \%$ formalin. Gross examination of placenta performed and then the section of placenta was stained with hematoxylin \& eosin stain. The consultant pathologist reviewed the slides. All the data was recorded on predesigned Performa and analyzed through SPSS version 11.0. Results: Among 124 cases, majority of women (41.93\%) were in the age group $30-40$ years and presented at gestation age more than 37 weeks. $21.77 \%$ of patients were having placental infarcts of less than $3 \mathrm{~cm}$ and $18.54 \%$ of cases were having placental infarcts of more than $3 \mathrm{~cm} .79 .03 \%$ of babies born alive, $41.12 \%$ were preterm and stillbirth was a finding in $20.96 \%$ of cases. Overall frequency of placenta infarcts in patients was $40.32 \%$. Conclusion: Placental infarcts were seen in about $40.32 \%$ placentae of women with placental abruption. Association between placental infarcts and preterm babies and stillbirths was also significant.
\end{abstract}

Key words: $\quad$ Fetal Outcome, Placental Abruption, Placental Infarcts.

Article Citation: Dureshahwar, Afridi S, Akhter R, Ahmad I, Asghar S, Naheed S. Frequency of placental infarcts in patients with severe placental abruption. Professional Med J 2019; 26(10):1640-1644.DOI: 10.29309/TPMJ/2019.26.10.3042

\section{INTRODUCTION}

Placental Abruption is the cause of vaginal bleeding in later half of pregnancy. ${ }^{1}$ Incidence of placental abruption varies from $0.49 \%$ to $1.8 \%{ }^{2}$ and is an important cause of maternal mortality and morbidity. ${ }^{2}$ The incidence of placental abruption doubles in twin gestations. ${ }^{3}$

Abruptions are reflected in placenta in a significant way both macroscopically and microscopically. ${ }^{4}$ There is evidence of abruption in $4.5 \%$ of placenta from normal pregnancies, suggesting that small episodes of placental abruption are common. ${ }^{1}$ Minor areas of infarctions are seen in about $25 \%$ of placenta from normal pregnancies. ${ }^{5}$ Abruption involving more than $50 \%$ of placenta is frequently associated with fetal death. ${ }^{6}$
Placental abruption was thought as an acute event though data points towards abruption being the end result of chronic process started early in pregnancy. ${ }^{7}$ Placental abruption is result of chronic processes that are present throughout gestation and responsible for term placental abruption. Risk of placental abruption was the highest in the presence of both histological lesions and vaginal bleeding early in pregnancy. ${ }^{7}$

As placenta abruption is the result of placental infarcts which is a chronic process. The aim is to study infarcts and its different severity grades histopathologically in placenta from women with severe abruption. 
Keeping in mind the clinical implications it carries and as there is no local study available, this study shall be a helpful contribution to making guidelines for its management and thus in improving the outcome in subsequent pregnancy of women with abruptions.

\section{MATERIAL AND METHOD}

This descriptive study was conducted from January 2016 to July 2016 in the Department of Obstetrics \& Gynaecology, Postgraduate Medical Institute, Lady Reading Hospital Peshawar. Using WHO software, a sample size of 124 subjects for confidence level 95\% was selected and women admitted through emergency were included in the study who fulfill the operational definition of severe placental abruption. Women with multiple pregnancies, Polyhydramnios, those with history of medical disorders like diabetes, hematological diseases or causes of vaginal bleeding like placenta previa diagnosed on ultrasound were excluded.

After obtaining formal history and decision to include the patient in the study, blood loss was estimated through graduated jar. Assessment of amount of blood loss was on amount of blood loss at the time of admission and amount of blood loss after delivery. Placenta of the subject was collected from labour room of the wards. Placenta was weighed after removal of adherent blood, umbilical cord and extra placental membranes and was fixed in $10 \%$ formalin. The sample was allotted special code and then sent to histopathology laboratory of LRH Peshawar with proper care and coordination between unit and laboratory. Gross examination of placenta performed and then the section of placenta was stained with hematoxylin \& eosin stain. The consultant pathologist reviewed the slides. Placental infarct was stratified among the gestation age and age of mothers to see the effect modifiers.

All the data was recorded on a predesigned Performa and analyzed by using SPSS version 11.0.

\section{RESULT}

A total of 124 singleton pregnant women with sever placental abruptions were selected in accordance with the inclusion criteria. Majority of the women i.e. $41.93 \%$ were in the age group of 30-40 years. Age group 20-29 years was next in line with $32.25 \%$. $16.93 \%$ of cases were in age group $>40$ years and the least number of cases were seen in age group $<20$ years i.e. $8.87 \%$. Age wise distribution of patients is shown in Table-l.

Total Number of Patients $=124$

\begin{tabular}{|l|c|c|}
\hline \multicolumn{1}{|c|}{ Age (Years) } & Nos. of Patients & $\%$ Age \\
\hline$<25$ & 11 & $8.87 \%$ \\
\hline 20 to 29 & 40 & $32.25 \%$ \\
\hline 30 to 40 & 52 & $41.93 \%$ \\
\hline$>40$ & 21 & $16.93 \%$ \\
\hline Total & 124 & $100 \%$ \\
\hline \multicolumn{2}{|c|}{ Table-l. Age wise distribution of patients } \\
\hline
\end{tabular}

With regard to severity of placental infarcts, majority of patients $(59.67 \%)$ were having no placental infarct. $21.77 \%$ of patients were having placental infarcts of less than $3 \mathrm{~cm}$ and $18.54 \%$ of the patientshad placental infarcts of more than 3 cm. (Table-II)

Total Number of Patients $=124$

\begin{tabular}{|l|c|c|}
\hline \multicolumn{1}{|c|}{ Placental Infarcts } & Nos. of Patients & $\%$ Age \\
\hline Absent & 74 & $59.68 \%$ \\
\hline Area of less than 3cm & 27 & $21.77 \%$ \\
\hline Area of more than 3cm & 23 & $18.55 \%$ \\
\hline Total Table-Il. Severity of placental Infarcts \\
\hline \multicolumn{2}{|c|}{ Tal } \\
\hline
\end{tabular}

Overall frequency of placenta infarcts in patients with severe abruption was $40.32 \%$ and no placental infarcts were observed in $59.67 \%$ of cases. (Table-III)

Total Number of Patients $=124$

\begin{tabular}{|l|c|c|}
\hline Placental Infarcts & Nos. of Patients & $\%$ Age \\
\hline Yes & 50 & $40.32 \%$ \\
\hline No & 74 & $59.68 \%$ \\
\hline Total & 124 & $100 \%$ \\
\hline
\end{tabular}

Table-III. Overall frequency of placenta infarcts 
Among 124 cases, $79.03 \%$ of babies born alive, $41.12 \%$ were preterm and stillbirth was a finding in $20.96 \%$ of cases. (Table-IV)

Total Number of Patients $=124$

\begin{tabular}{|l|c|c|}
\hline \multicolumn{1}{|c|}{ Fetal Outcome } & Nos. of Patients & \%Age \\
\hline Preterm & 51 & $41.12 \%$ \\
\hline Alive & 98 & $79.03 \%$ \\
\hline Stillbirth & 26 & $20.96 \%$ \\
\hline \multicolumn{2}{|r|}{} \\
\hline
\end{tabular}

Stratification according to age and gestational age is shown in Table-V.

Total Number of Patients $=124$

\begin{tabular}{|c|c|c|c|}
\hline $\begin{array}{l}\text { Age Group } \\
\text { (in Years) }\end{array}$ & $\begin{array}{l}\text { Placental } \\
\text { Infarcts } \\
\text { (Yes) }\end{array}$ & $\begin{array}{l}\text { Placental } \\
\text { Infarcts } \\
\text { (No) }\end{array}$ & P-Value \\
\hline$<20$ & 4 & 7 & \multirow{4}{*}{$\begin{array}{c}\text { Chi-square } \\
\text { value }=0.1295 \\
d f=3 \\
\text { p value }=0.9880\end{array}$} \\
\hline $20-29$ & 16 & 24 & \\
\hline $30-40$ & 21 & 31 & \\
\hline$>40$ & 9 & 12 & \\
\hline \multicolumn{4}{|c|}{ Gestational age at presentation } \\
\hline$<37$ weeks & 21 & 30 & \multirow{2}{*}{$\begin{array}{c}\text { Chi-square } \\
\text { value }=0.0262 \\
d f=1 \\
\text { p value }=0.8712\end{array}$} \\
\hline$>37$ weeks & 29 & 44 & \\
\hline & $\begin{array}{r}\text { Stratificati } \\
\text { gest }\end{array}$ & according & to age and \\
\hline
\end{tabular}

\section{DISCUSSION}

Placental abruption is one of the most common causes of late pregnancy bleeding. ${ }^{8}$ In humans, it refers to the abnormal separation after 20 weeks of gestation and prior to birth. ${ }^{9}$ Placental abruption usually presents as combination of vaginal bleeding, uterine contractions, and pain. ${ }^{10}$ The perinatal mortality rate varies between $20 \%$ and $67 \%$, depending on gestational age, fetal weight, and the degree of abruption. ${ }^{11}$ About half of perinatal deaths due to placental abruption occur in, which also makes this disorder a major contributor to stillbirth. ${ }^{12}$

In this study higher percentage (41.93\%) of patients falling in age group of $30-40$ years is supportive of another local study conducted in Pakistan where placental abruption was more common in age group $31-40$ years $^{13}$ and is also comparable with another study from Pakistan in which $44.37 \%$ patients were in the age group of 36-40 years. ${ }^{14}$ Other International and National studies have reported that pregnant women who are younger than 20 or older than 35 years had greater risk for placental abruption. ${ }^{15}$ Similarly, a study reported that mothers with infarcts tended to be younger than those without infarcts. ${ }^{16}$

With regard to gestational age at presentation, the outcome of this study indicating higher percentage $(58.87 \%)$ at gestation age less than 37 weeks is inconsistent to another study conducted in Pakistan, where most of the women who presented with abruptio placenta had gestational age $<36$ weeks. ${ }^{17}$ Krishna Menon ${ }^{18}$ found the highest incidence among the same subgroup while Parikh MN found higher incidence among 37 weeks and above. ${ }^{19}$

Considering the severity of the placental infarct and overall frequency of placental infarcts in patients with severe abruption, the results of our study are comparable with an International study, where severity of placental infarct was mild in 10.25\%, 33.3\% moderate and 59\% severe. Similar finding was noted by Bandana Das et al in $1996 .^{20}$

Overall frequency of placenta infarcts in the present study with severe abruption was $40.32 \%$ and no placental infarcts were observed in $59.67 \%$ of cases. Tuzovic et $\mathrm{al}^{21}$ had recorded $29 \%$ cases of placental infarcts while Bhatia et al had recorded $30 \%$ cases of placental infarcts which is comparable with our results. Another International study reported incidence of placental infarcts in $29 \%$ of cases. ${ }^{22}$

Regarding outcome of patients with placental infarct, the results generated by another local study from Pakistan showed that in 90 patients whose placentas were infarct free, $91.11 \%(n=82)$ fetuses were alive and $8.88 \%(n-8)$ fetuses were still-born. ${ }^{23}$ Fetal outcome in 40 patients whose placentas showed infarct was that $70 \%(n=28)$ fetuses were alive and $30 \%(n=12)$ fetuses were 
still-born. ${ }^{23}$ Similar results were found in study done by Bhatia ${ }^{24}$ in which infarction was present in $5 \%$ of controls and the association of still birth with infarction was highly statistically significant.

\section{CONCLUSION}

Frequency of placental infarcts is quite high in patients with severe abruption. There is significant association between placental infarcts and preterm babies and stillbirths. Severe placental infarcts have an adverse effect on the fetal outcome.

Copyright@ 15 Mar, 2019.

\section{REFRENCES}

1. Oyelese Y, Ananth CV. Placental abruption. Obstet Gynecol. 2006; 108:I00516.

2. Konje JC, Taylor DT. Placental abruption. In: James DK, Steer PL, Weiner CP, Gonik B, editors. High risk pregnancy: Management options. 3fh ed. Philadelphia: Saunders; 2006 P.1266-70.

3. Yeo L, Ananth CV, Vintzileos AM. Placental abruption [Online]. 2008 [cited on 2012 Feb 12]. Available from URL: http://www.glowm.com/?p=glowm.cm1/section_ view\&articleid $=122$.

4. Elsasser DA, Ananth CV, Prasad V, Vintzileos AM. Diagnosis of placental abruption: Relationship between clinical and histopatliological findings. Eur J Obstet Gynecol Reprod Biol. 2010; 148:125-130.

5. Nath CA, Ananth CV, Smulian JC, Shen-Schwarz S, Kaminsky L. Histologic evidence of inflammation and risk of placental abruption. Am J Obstet Gynecol. 2007; 197:319.el-6.

6. Ananth CV, Oyelese Y, Prasad V, Getahun D, Smulian JC. Evidence of placental abruption as a chronic process: association with vaginal bleeding early in pregnancy and placental lesions. Eur $\mathrm{J}$ Obstet Gynecol Reprod Biol. 2006; 128:15-21.

7. Ananth CV, Getahun D, Peltier MR, Smulian JC. Placental abruption in term and preterm gestations: Evidence for heterogeneity in clinical pathways. Obstet Gynecol. 2006; 107:785-92.

8. Sakornbut E, Leeman L, Fontaine P. Late pregnancy bleeding. Am Fam Physician. 2007; 75:1199-206.

9. Lindqvist PG, Happach C. Risk and risk estimation of placental abruption. Eur J Obstet Gynecol Reprod Biol. 2006; 126:160-4.
10. Fiori O, Verstraete L, Berkane N. Risk factors of abruption placentae among Peruvian women. Am J Obstet Gynecol. 2007; 196:e15.

11. Aninth CV, Getahun D, Peltier MR, Smulian JC. Placental abruption in term and preterm gestations: Evidence for heterogeneity in clinical pathways. Obstet Gynecol. 2006; 107:785-92.

12. Sesbuppha W, Chantip S, Dick EJ, Jr, SchlabritzLoutsevitch NE, Guardado-Mendoza R, Butler SD, et al. Still births in Macacafascicularis. J Med Primatol. 2008; 37:169-72.

13. Talpur NN, Memon SR, Jamro B, Korejo R. Maternal and fetal morbidity with abruption placentae. RMJ. 2011; 36(4): 297-300.

14. Jabeen M, Gul F. Abruption Placentae: Risk factors and perinatal outcome. J Postgrad Med Inst. 2004; 18(4):669-76.

15. Zamani E. Kerman, Iran: School of Medicine, Kerman University of Medical Sciences; 2009. Study of the frequency of obstetrical antepartum hemorrhage and the causes among pregnant patients at tending the center of Afzalipoor Hospital, Kerman. PhD Thesis.

16. Blair E, de Groot J, Nelson KB. Placental infarction identified by macroscopic examination and risk of cerebral palsy in infants at $\mathbf{3 5}$ weeks of gestational age and over. Am J Obstet Gynecol 2011; 205:1 24.e17.

17. ShaistaFarooq, Razia Mustafa Abbasi, Naushaba Rizwan, Firdous Mumtaz. Feto maternal outcome among Abruptio Placentae cases at a university hospital of Sindh. J LiaquatUni Med Health Sci May Aug 2008; 7(2):106-9.

18. Menon MK et al: Accidental Haemorrhage. J Obstet Gynecol. 1961; 11:335-53.

19. Parikh MN, Masani KM. Accidental haemorrhage. J Obstet Gynecol.1961; 11:38.

20. Bandana Das, D. Dutta, S. Chakraborthy, P. Nath. Placental morphology in hypertensive disorders of pregnancy and its correlation with fetal outcome. J Obstet and Gynecol India, 1996; 46(1):40-46.

21. Tuzovic L, Djelmis J, Ilijic M. Placenta infarct: Case control study. Croat Med J 2003:44:728-33.

22. Udainia A, Bhagwat SS, Mehta CD. Relation between placental surface area, infarction and foetal distress in pregnancy induced hypertension with its clinical relevance. J AnatSoc India. 2004; 53(1):27-30. 
23. Rafiq S, Rahim R, Raees M. Correlation of adverse perinatal outcomes and placental infarcts in hypertensive primigravida mothers. JPMI. 2013; $27(3): 322-5$.
24. Bhatia A, Sharma SD, Jalnawalla SF. A com - parative study of placental infarct and fetal out-come. Indian J PatholMicobiol. 2007; 24:277-83.

\section{AUTHORSHIP AND CONTRIBUTION DECLARATION}

\begin{tabular}{|c|c|c|c|}
\hline Sr. \# & Author-s Full Name & Contribution to the paper & Author's Signature \\
\hline 1 & Dureshahwar & $\begin{array}{l}\text { Concept and design of the study, } \\
\text { Final approval and guarantor of the } \\
\text { article. }\end{array}$ & Qluar \\
\hline 2 & Sanodia Afridi & $\begin{array}{l}\text { Collection and assembly of data, } \\
\text { Interpretation of the data. }\end{array}$ & nodia \\
\hline 3 & Rubina Akhter & $\begin{array}{l}\text { Critical revision of the article for } \\
\text { important intellectual content. }\end{array}$ & \\
\hline 4 & Irshad Ahmad & $\begin{array}{l}\text { Statistical expertise and english } \\
\text { language proof reading. }\end{array}$ & \\
\hline 5 & Sajida Asghar & $\begin{array}{l}\text { Critical revision of the article for } \\
\text { important intellectual content. }\end{array}$ & \\
\hline 6 & Saniya Naheed & $\begin{array}{l}\text { Collection, assembly and } \\
\text { interpretation of data. }\end{array}$ & \\
\hline
\end{tabular}

